\title{
PERBANDINGAN FITUR PADA PLATFORM KUIS TERPOPULER
}

\author{
M. Chandra C. Utomo ${ }^{1}$, M. Gilvy L. Putra ${ }^{2}$, dan Dwi A. Prambudi ${ }^{3}$ \\ Program Studi Informatika, Institut Teknologi Kalimantan ${ }^{1}$ \\ Email : ccahyo@lecturer.itk.ac.id ${ }^{1}$, gilvy.langgawan@lecturer.itk.ac.id ${ }^{2}$, \\ dwiariefprambudi@lecturer.itk.ac.id ${ }^{3}$
}

\begin{abstract}
ABSTRAK
Karena wabah COVID-19, banyak sekolah yang menerapkan kegiatan belajar secara daring di rumah. Karena siswa belajar di rumah, guru harus memberikan soal latihan secara daring atau semacamnya. Hal tersebut perlu dilakukan untuk mengukur tingkat pemahaman siswa. Google Forms, Microsoft Office Forms, Kahoot, dan Quizizz mampu menyediakan kuis secara daring. Masing-masing platform tersebut memiliki poin keunggulannya sendiri. Studi ini membandingkan dan menjelaskan hal-hal apa saja yang mampu dilakukan oleh masing-masing platform kuis daring tersebut. Tiga fokus utama dalam perbandingan tersebut yaitu dari segi variasi soal yang bisa ditampilkan, kemudahan dalam memahami dan mengolah skor hasil kuis, dan batasan dalam pengerjaan kuis seperti kapan harus dikerjakan serta durasi pengerjaannya. Selain itu, studi ini akan memberikan rekomendasi platform terbaik sesuai dengan kebutuhan Anda. Berdasarkan hasil perbandingan maka Google Forms merupakan platform yang paling banyak fitur untuk berbagai macam keperluan. Tetapi apabila Anda ingin memberikan pengalaman belajar yang baru dan menyenangkan kepada siswa-siswinya maka kami menyarankan Anda supaya menggunakan platform Kahoot.
\end{abstract}

Kata Kunci: Forms, Google, Kahoot, Microsoft, Quizizz

\section{ABSTRACT}

Because of the COVID-19 outbreak, many schools are applying an online learning activity at home. Because the students are learning at home, the teacher must bring the online exercise or something like that to measure the student's knowledge. Google Forms, Microsoft Office Forms, Kahoot, and Quizizz can provide online quizzes, but these platforms have their own value point. This study is comparing and mapping the value points of these online quizzes' platforms. The three main focuses in the comparison, are the variety of questions that can be displayed, the ease of understanding and processing the score of the quiz results, and the limitations in taking the quiz, such as when to do it and the duration of the quiz. Also, this study will give the recommendation of the best platform depending on your needs. Based on the comparison, Google Forms is the most featured platform for various purposes. But if you want to provide a new and enjoyable learning experience for your students, we recommend that you use the Kahoot platform.

Keywords: Forms, Google, Kahoot, Microsoft, Quizizz

\section{PENDAHULUAN}

Platform kuis daring mulai sering digunakan belakangan ini. Penyebabnya karena wabah COVID-19. Untuk mencegah penyebaran wabah COVID-19, maka pemerintah mencoba melakukan penyelesaian dengan bentuk physical distancing dan karantina mandiri 
(Maharani, 2020; Ihsanuddin, 2020). Hal ini menyebabkan banyak siswa belajar di rumah (Tariyah, 2020). Dalam situasi ini, banyak guru yang masih perlu membawa latihan untuk siswanya. Latihan selalu dibutuhkan untuk mengukur pengetahuan siswa. Semakin tinggi pengetahuan siswa, yang dapat dibuktikan dengan nilai latihan maka semakin baik pengajarannya (Kusumo, Sabariah, \& Wiharja, 2017; Pambudi, \& Bariyah, 2020).

Dalam kondisi yang tiba-tiba berubah karena wabah COVID-19, banyak guruguru dan tenaga pengajar yang bingung dan kesulitan beradaptasi. Di antara guru-guru dan tenaga pengajar tersebut membutuhkan media yang menyenangkan dalam mengevaluasi pengetahuan siswa-siswinya (Yunanto, Alfiansyah, Kanza, Fauzia, \& Prastiani, 2020). Di antara guru-guru dan tenaga pengajar tersebut kurang berkenan untuk mencoba berbagai macam platform kuis daring yang ditawarkan di internet. Alasan utamanya adalah terlalu menyita waktu mereka. Mereka pasti akan dipaksa untuk membuat akun terlebih dahulu di platform tersebut, mencoba-coba berbagai fitur yang sering kali sulit dipahami dan tidak memiliki panduan tentang bagaimana cara menggunakan, hingga kesimpulan yang dapat kurang memuaskan mereka setelah meluangkan waktu untuk mencobacoba platform tersebut (Muzaki, Puspitasari, \& Indriati, 2019). Oleh karena itu penelitian ini dimaksudkan untuk memberikan uraian dan penjelasan terkait fitur-fitur yang ditawarkan beserta perbandingannya kelebihan dan kekurangannya. Diharapkan hasil dari penelitian ini bagi guru-guru dan tenaga pendidik mendapatkan gambaran terkait beberapa platform kuis terpopuler dan menentukan sendiri platform yang paling sesuai bagi mereka tanpa harus mencobanya sendiri satu persatu.

Google Forms, Microsoft Office Forms, Kahoot, dan Quizizz mampu menyediakan platform online untuk menyajikan beberapa latihan atau kuis. Tetapi masing-masing dari mereka memiliki poin nilainya sendiri. Guru harus mengetahui poin-poin nilai ini untuk memberikan metode latihan terbaik. Dalam kasus ini, kami akan fokus untuk membandingkan dan memetakan fitur dan poin nilai platform ini. Semoga pembelajaran ini dapat bermanfaat bagi banyak guru yang ingin memberikan latihan kepada siswanya.

\section{METODE PENELITIAN}

Metode penelitian diperlukan agar Penelitian dapat dilaksanakan secara cermat dan terencana dalam memahami dan mendalami objek yang sedang dikaji. Penelitian ini menggunakan metode deskripsi komparatif dengan pendekatan kuantitatif, kualitatif, dan survei. Metode penelitian secara komparatif dilakukan dengan cara membandingkan persamaan dan perbedaan pada masing-masing objek yang dikaji, dalam hal ini adalah keempat platform kuis daring. Pendekatan kuantitatif yang dimaksud adalah kami akan menyebutkan satu-persatu fitur-fitur yang mampu dilakukan dan yang tidak mampu dilakukan oleh masing-masing platform. Pendekatan kualitatif yang dimaksud adalah kami akan membandingkan tingkat efektivitas dan efisiensi fitur-fitur yang serupa yang dimiliki oleh masing-masing platform. Pendekatan survei yang dimaksud adalah kami akan meminta bantuan ke beberapa 
orang awam untuk melakukan perbandingan sesuai kemampuan mereka agar hasil perbandingan menjadi lebih objektif. Studi ini dimulai dengan mengumpulkan fitur-fitur apa saja yang dimiliki oleh masing-masing platform, kemudian mencoba semua kemampuan fitur-fitur tersebut, dan kemudian membandingkan fitur-fitur tersebut dengan fitur-fitur sejenis dari platform lain. Setelah diketahui perbandingan masing-masing fitur dari masing-masing platform maka selanjutnya dilakukan analisis dan pembahasan terhadap masing-masing fitur tersebut. Analisis dan pembahasan dilakukan dengan cara membandingkan masing-masing fitur dari masing-masing platform secara kuantitatif dan kualitatif. Secara kuantitatif yaitu tentang seberapa banyak fitur yang dimiliki oleh platform tersebut. Semakin banyak maka semakin baik bagi platform tersebut dalam memenuhi berbagai macam kebutuhan pengguna. Secara kualitatif yaitu tentang seberapa baik dan efektif fitur tersebut dalam memuaskan kebutuhan pengguna.

\section{FITUR-FITUR PLATFORM}

Masing-masing Google Forms (GForms), Microsoft Office Forms (OForms), Kahoot, dan Quizizz adalah platform gratis, tetapi Kahoot memiliki metode berbayar untuk mendapatkan lebih banyak fitur. Semua fitur tersebut dapat dilihat pada Lampiran 1. Beberapa fitur Kahoot yang mengharuskan Anda membayar akun premium adalah laporan skor berbasis web, pertanyaan polling, dan pertanyaan tipe. Dengan akun gratis, berbasis web memberikan laporan ringkasan terbatas, tanpa polling, dan tanpa pertanyaan tipe.
Dari Lampiran 1, semua platform mampu menyajikan kuis dengan pertanyaan pilihan ganda. Baik G-Forms dan Kahoot dapat menyajikan pertanyaan pilihan ganda dengan lebih dari satu jawaban yang benar, tetapi O-Forms dan Quizizz tidak bisa. Tiga dari G-Forms, OForms, dan Quizizz dapat melayani pertanyaan kotak centang tetapi Kahoot tidak bisa. Setiap platform dapat melayani pertanyaan polling dan pertanyaan uraian. Pertanyaan uraian sangat berguna jika pertanyaannya adalah pertanyaan matematika. Selain itu, O-Forms dan Kahoot dapat melayani pertanyaanpertanyaan yang sensitif dengan urutan jawaban, di mana siswa harus menyusun ulang jawaban tersebut ke urutan yang benar. Semua platform dapat mengacak urutan pertanyaan dan / atau urutan jawaban pada setiap pertanyaan. Setiap platform dapat membuat laporan lengkap dan dapat ditampilkan di web juga dapat diunduh dalam format XLSX.

Baik Kahoot dan Quizizz dirancang untuk melayani mode kuis langsung (live quiz), di mana kuis diberikan oleh guru kepada siswa di dalam kelas. Selain itu, Kahoot dan Quizizz dapat melayani kuis yang dibawa pulang, begitu pula dengan GForms dan O-Forms. Baik G-Forms dan OForms tidak dapat mencegah siswa mundur ke pertanyaan sebelumnya. Jika tidak, Kahoot tidak bisa membiarkan siswa mundur ke pertanyaan sebelumnya. Secara default, Quizizz tidak mengizinkannya, jika siswa tidak dapat melakukan power-up. Ini adalah kondisi langka untuk mendapatkan power-up. Karena Kahoot dan Quizizz dirancang untuk melayani kuis langsung, platform ini dapat menyetel batas waktu 
untuk setiap pertanyaan, tetapi G-Forms tidak.

Dalam kuis mode bawa pulang, semua platform dapat menampilkan atau menyembunyikan jawaban yang benar kepada siswa, tetapi Kahoot tidak dapat menyembunyikannya. Jawaban yang benar akan ditampilkan setelah setiap pertanyaan. Hanya G-Forms yang dapat memberikan masukan yang berbeda berdasarkan jawaban yang dipilih. Secara default, GForms tidak dapat menayangkan kuis mulai otomatis dan berhenti otomatis, tetapi dengan addon, hal tersebut bisa dilakukan. Baik Kahoot dan Quizizz hanya dapat melayani penghentian otomatis tetapi tidak ada pengaktifan otomatis, tetapi O-Forms dapat melakukan keduanya. G-Forms, OForms, dan Quizizz dapat menyediakan pengguna anonim untuk mengikuti kuis. Tetapi jika kita hanya membutuhkan pengguna tertentu yang dapat mengirimkan jawabannya, pengguna tersebut harus terdaftar terlebih dahulu. Di Quizizz, setelah pengguna tersebut terdaftar, pengguna tersebut harus terdaftar di kelas yang diberikan oleh guru. O-Forms dapat menyediakan pengguna anonim untuk mengikuti kuis juga, tetapi O-Forms tidak dapat membatasi kuis untuk pengguna tertentu yang tidak dikehendaki.

\section{HASIL DAN PEMBAHASAN}

G-Forms dapat melayani pertanyaan pilihan ganda, pertanyaan kotak centang, pertanyaan polling, dan pertanyaan uraian. Lebih dari itu, pertanyaan pilihan ganda mampu memberikan banyak pilihan (dan mungkin tidak terbatas), dan begitu juga pada pertanyaan kotak centang. Selain itu, pertanyaan pilihan ganda dan pertanyaan kotak centang dapat dibuat seperti pertanyaan skala. Petak pertanyaan skala bisa dibuat seperti vektor atau skala 2 dimensi. Jawaban yang benar hanya dapat menetapkan satu atau beberapa jawaban. Selain itu, G-Forms dapat menyajikan pertanyaan uraian dengan banyak alternatif (dan mungkin tidak terbatas) dari jawaban yang benar. Umpan balik yang berbeda dapat dibuat berdasarkan setiap jawaban. Untuk itulah Google Forms sangat cocok untuk membuat berbagai macam pertanyaan.

Kahoot dapat melayani pertanyaan pilihan ganda, pertanyaan polling, dan pertanyaan uraian. Seperti G-Forms, Kahoot dapat memberikan beberapa jawaban yang benar pada pertanyaan pilihan ganda. Tapi Kahoot tidak bisa melayani pertanyaan kotak centang atau pertanyaan skala. Selain itu, Kahoot dan OForms mampu melayani pertanyaanpertanyaan yang sensitif dengan urutan jawaban. Jenis pertanyaan ini sangat unik karena menantang siswa untuk mengingat dan memahami urutan ilmu. Tapi pertanyaan semacam ini masih bisa diberikan dengan G-Forms menggunakan metode rumit dari pertanyaan skala 2 dimensi.

Dalam laporan kuis (quiz report), semua platform dapat membuat laporan lengkap. Laporan yang diunduh yang dibuat oleh G-Forms adalah laporan yang paling sederhana daripada Kahoot dan Quizizz. Laporan tersebut hanya memberikan informasi tentang jawaban dan skor masing-masing siswa. Skor pada GForms dapat diatur pada setiap pertanyaan dan dapat diatur secara otomatis atau manual. Dalam laporan berbasis web, GForms dapat menampilkan ringkasan skor distribusi sebagai grafik dan pertanyaan 
mana yang mudah dan pertanyaan mana yang sulit. Fitur ini cukup bagi kita, selama kita mampu menyajikan auto scoring dan memberikan skor total tiap siswa (Sari, \& Muhartini, 2017; Kusuma, \& Widodo,2016).

Sebagai kuis langsung dalam desain, penilaian otomatis bervariasi tergantung pada seberapa cepat dan benar seorang siswa menjawab. Quizizz dapat memberikan lebih banyak laporan informasi dengan analisis sederhana. Selain memberikan semua jawaban dan skor, juga memberikan persentase ketelitian setiap siswa. Dalam dunia web Quizizz ibarat GForms yang dapat memberikan ringkasan soal mana yang mudah dan mana yang sulit. Selain itu, Quizizz dapat menunjukkan peringkat siswa berdasarkan skor total. Secara teknis, laporan Kahoot mirip dengan Quizizz, tetapi Kahoot mencatat lebih banyak informasi seperti waktu menjawab dalam hitungan detik. Juga dalam laporan yang diunduh, Kahoot menulis lebih banyak informasi seperti detail pertanyaan dengan jawaban yang benar, semua jawaban yang dapat dipilih, durasi, dan banyak lagi. Dalam web-based, Kahoot memberikan informasi tentang distribusi waktu menjawab tiap soal dan grafik progress skor tiap siswa dari satu soal ke soal lainnya. Pada titik ini, Kahoot adalah yang terbaik.

Kahoot benar-benar dirancang untuk menjadi kuis langsung. Guru harus memproyeksikan dasbor di depan kelas. Dasbor memperlihatkan pertanyaan, jawaban yang dapat dipilih, dan peringkat. Dengan desain ini, guru dapat memberikan umpan balik dan interaksi langsung kepada siswa. Dalam Quizizz, dashboard hanya ditampilkan peringkat kemudian pertanyaan dan jawaban ditampilkan di perangkat masing-masing siswa. Mekanisme pemeringkatan mampu mendongkrak gengsi sebagai siswa yang cerdas. Untuk itu, Kahoot menjadi pilihan yang tepat untuk merangsang minat belajar siswa (Purnomo, 2016). Tapi jika internet masalahnya, Quizizz bisa menjadi alternatif.

Karena Kahoot benar-benar dirancang untuk menjadi kuis langsung, Kahoot tidak dapat menyembunyikan jawaban yang benar. Tidak ada konfigurasi untuk menyembunyikan jawaban yang benar, dan tetap muncul setelah setiap pertanyaan tidak peduli modenya dipilih. Jika mode disetel ke kuis dibawa pulang, ini dapat menyebabkan kebocoran jawaban yang benar di antara siswa. Dibandingkan dengan yang lain, G-Forms dan Quizizz dapat menyembunyikan jawaban yang benar. Sebagai kuis langsung dalam desain, Kahoot dan Quizizz dapat mencegah siswa mundur ke pertanyaan sebelumnya tetapi G-Forms tidak bisa. Jika G-Forms dipilih untuk membuat kuis bawa pulang dengan pengacakan urutan pertanyaan, ini dapat menyebabkan pengacakan menjadi kurang efektif. Hal tersebut dapat menyebabkan siswa saling berdiskusi dan mengoreksi jawaban. Untuk alasan ini, Quizizz lebih cocok untuk membuat kuis yang dibawa pulang.

Selain itu, Quizizz memiliki fitur untuk menampilkan meme dan memberi powerup. Meme ditampilkan setelah setiap pertanyaan sedangkan power-up diberikan secara acak jika siswa telah memilih jawaban yang benar. Fitur tersebut diaktifkan secara default untuk membuat kuis menjadi lebih menyenangkan di beberapa kondisi. Namun di sektor 
pendidikan, fitur tersebut tidak berguna dan harus dinonaktifkan.

Di sisi lain, O-Forms mirip seperti GForms. O-Forms dapat menyajikan pertanyaan-pertanyaan yang sensitif dengan urutan jawaban, sedangkan GForms tidak bisa. Tapi O-Forms tidak dapat menyajikan pertanyaan pilihan ganda dengan lebih dari satu jawaban yang benar. Pertanyaan kotak centang tidak bisa dibuat seperti pertanyaan skala 2 dimensi. Tapi OForms memiliki gaya pertanyaan skala 1 dimensi yang lain. Alih-alih gaya tombol radio standar, ia memiliki gaya bintang. Selain itu, O-Forms memiliki pengalaman pengguna yang lebih mudah daripada yang lain dan meletakkannya di platform terbaik untuk pengguna pertama kali. Namun minimnya batasan pengguna yang bisa mengikuti kuis masih membutuhkan metode yang rumit.

Berdasarkan pembahasan di paragraf sebelumnya maka diketahui bahwa Kahoot memiliki 2 kelebihan yang dijelaskan dalam 2 paragraf, kemudian Quizizz memiliki 1 kelebihan yang dijelaskan dalam 1 paragraf, sedangkan yang lain mungkin hanya unggul di desain antarmukanya saja. Agar hasil penelitian lebih objektif maka penulis melakukan survei kepada 11 orang yang bersedia berpartisipasi. Dari 11 orang yang bersedia berpartisipasi, kesebelas orang tersebut sama-sama memilih G-Forms sebagai platform yang paling diminati. Alasannya adalah karena akun Google merupakan akun yang bisa dibilang semua orang pasti punya, sehingga tidak perlu lagi mendaftar dan membuat akun baru. Selain itu desain antarmuka pengguna untuk platform GForms juga sudah dirasa familiar sehingga pengguna tidak perlu mempelajarinya lagi.
Ketika kesebelas orang tersebut ditawarkan pada desain antarmuka O-Forms, mereka setuju bahwa platform O-Forms lebih mudah digunakan. Akan tetapi karena mereka sudah terlanjur familiar dengan GForms maka mereka kemungkinan masih cenderung menggunakan G-Forms.

Kesebelas partisipan tersebut kemudian ditawarkan hanya pada pilihan antara Kahoot dan Quizizz terhadap kelebihannya yaitu menyelenggarakan kuis secara langsung (live quiz). 8 orang partisipan lebih memilih Kahoot dengan alasan yaitu desain antarmukanya yang lebih nyaman. Beberapa di antaranya menyebutkan bahwa warna-warnanya lebih atraktif, lucu, dan tetap terkesan elegan dan profesional. Selain itu penempatan menumenu beserta keterangannya lebih mudah dipahami. 3 orang partisipan sisanya lebih memilih Quizizz dengan alasan yaitu lebih ringan diakses dan masih belum ada biaya tambahan untuk dapat memakai semua fitur-fiturnya.

\section{SIMPULAN DAN SARAN}

Secara umum, Google Formulir adalah pilihan terbaik. Ia mampu memberikan berbagai jenis pertanyaan seperti pertanyaan pilihan ganda, pertanyaan kotak centang, pertanyaan polling, pertanyaan uraian, dan pertanyaan skala. Selain itu, Google Formulir mampu memberikan umpan balik yang berbeda berdasarkan setiap jawaban. Jika Anda membutuhkan platform kuis langsung (live quiz), Kahoot adalah pilihan terbaik. Setiap pertanyaan diikuti dengan pilihan jawaban dan peringkat yang ditampilkan di dasbor dapat membuat kelas lebih interaktif. Selain itu, laporan yang diunduh sangat informatif. Quizizz sangat berguna jika Anda 
membutuhkan kuis yang dibawa pulang dengan aturan yang ketat dan Office Forms lebih baik bagi orang awam untuk membuat kuis.

Keputusan terakhir terhadap platform mana yang terbaik jatuh pada pilihan Anda sendiri. Secara subjektif, kami sangat menyarankan agar menggunakan Kahoot sebagai platform untuk menyelenggarakan kuis daring. Fitur untuk menyelenggarakan kuis secara langsung (live quiz) merupakan fitur yang sangat menyenangkan dan memicu interaksi antara guru dan siswanya, serta akan memberikan pengalaman baru terhadap metode belajar mengajar.

\section{DAFTAR PUSTAKA}

Ihsanuddin. (2020). Jokowi Nilai Perlu Physical Distancing Skala Besar Disertai Kebijakan Darurat Sipil, Kompas, https://nasional.kompas.com/read/202 0/03/30/14513531/jokowi-nilai-perluphysical-distancing-skala-besardisertai-kebijakan, retrieved April 10, 2020.

Kusuma, A. P., \& Widodo, T. (2016). "Rancang Bangun Sistem Pendataan Nilai Akademik Siswa berbasis Web menggunakan PHP dan MySQL di SMA Islam Hasanuddin Kesamben", Antivirus Jurnal Ilmiah Teknik Informatika, vol.10. no.1.

Kusumo, D. S., Sabariah, M. K., \& Wiharja, K. R. S. (2017). A Goal Question Metric (GQM) Approach for Evaluating Interaction Design Patterns in Drawing Games for Preschool Children, Jurnal Ilmu Komputer dan Informasi, vol. 10, pp. 96-101.

Maharani, T. (2020). Jubir Pemerintah: Penerapan Physical Distancing Diperkuat Melalui Kebijakan PSBB, Kompas, https://nasional.kompas.com/read/202 0/04/10/18195851/jubir-pemerintahpenerapan-physical-distancingdiperkuat-melalui-kebijakan, retrieved April 10, 2020.

Muzaki, M. N., Puspitasari, M. D. M., \& Indriati, R. (2019). Sistem Informasi Dokumen Pendukung Ujian Akhir Semester, Antivirus Jurnal Ilmiah Teknik Informatika, vol.13. no.2.

Pambudi, D. S., \& Bariyah, T. (2020). Student Attendance System using WIFI Direct and Temporary WI-FI Hotspot. Jurnal Ilmu Komputer dan Informasi, vol. 13, pp. 1-8.

Purnomo, M. T. C. S. (2016). Perancangan dan Implementasi Game Interaktif Pengenalan Huruf dan Angka untuk Media Pembelajaran di PAUD Wachid Hasyim Ponggok Kabupaten Blitar. Antivirus Jurnal Ilmiah Teknik Informatika, vol.10. no.1.

Sari, H. P., \& Muhartini, R. (2017). Sistem Aplikasi Pengolahan Nilai Raport SDN Tanjunganom 2 Kecamatan Tanjunganom Nganjuk. Antivirus Jurnal Ilmiah Teknik Informatika, vol.11. no.1.

Tariyah. (2020). Kebijakan Bekerja Dari Rumah dan Pelayanan Publik, Ombudsman Republik Indonesia, https://www.ombudsman.go.id/artikel /r/artikel--kebijakan-bekerja-darirumah-dan-pelayanan-publik, retrieved April 10, 2020.

Yunanto, A. A., Alfiansyah, M. F., Kanza, R. A., Fauzia, K. V., \& Prastiani, S. A. T. (2020). Aplikasi Pembelajaran untuk Orang Tua dalam Mendidik Anak. Antivirus Jurnal Ilmiah Teknik Informatika, vol.14. no.2. 